\title{
High Voltage DC Breaker Requirements for Radial HVDC Network Applications
}

\author{
K. Tahata, S. Ka, K. Kamei, K. Kikuchi, M. Miyashita, D. Yoshida, Y. Kono, H. Ito \\ Mitsubishi Electric Co., Japan
}

\begin{abstract}
High Voltage Direct Current (HVDC) transmission has been expanding due to rapid development of power electronics technology and by the need for connection of offshore or remote wind farms and / or large hydro power generators. HVDC transmission has several benefits such as lower transmission losses, fewer lines required for the same power transmission, and less system stability problems.

Multi-terminal HVDC systems require maintaining operable converter stations connected to healthy lines, when DC fault occurs at a remote terminal. To ensure such operability, DC circuit breakers (DCCB) are indispensable and their fault clearing times are crucial. The fault clearing times vary depending on the system configuration (radial or meshed network), design parameters of the voltage source converter (VSC), transmission capacity, presence of series connected reactor and impedance of line / cable. However, DCCBs are required to clear the fault with a shorter time as compared with AC circuit breakers.

In this paper, the requirements for DCCB were analytically evaluated using a four-terminal radial HVDC network model. The results show that DC fault interruption current and fault clearing time are achievable by a mechanical DCCB with the forced current zero formation scheme.
\end{abstract}

Keywords-HVDC Grid; DC current interruption; mechanical DC circuit breaker; Forced current zero formation scheme; fault clearing time; series-connected reactor.

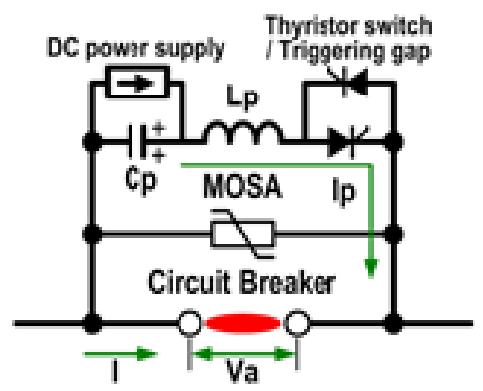

\section{INTRODUCTION}

HVDC transmission has been expanding due to rapid development of power electronics technology and by the need for connection of offshore or remote wind farms and / or large hydro power generators. CIGRE, the International Council on Large Electric Systems, established various Working Groups (WG) and leads the HVDC investigations. For example, WG B4.52 summarized a feasibility study of HVDC and B4/B5.59 is investigating control and protection of HVDC grids. They will provide a platform for greater engagement of other SCs on HVDC grid issues. Furthermore, a joint WG A3/B4.34 on DC switchgear potentially applicable to future HVDC grids have been recently established. The WG will investigate focusing especially on the possibility of a mechanical DC circuit breaker with different technologies. [1],[2],[3],[4],[5]

DC fault current can be interrupted when the current is forced to zero crossing. Figure 1 shows one of the representative schemes for the current zero formation. This scheme is called forced current zero formation. This scheme can be potentially applicable to interrupt the High-voltage DC fault current where a large-capacity capacitor is required to interrupt the DC current. The active resonant circuit composing of a pre-charged external capacitor imposes a high frequency (several $\mathrm{kHz}$ ) reverse current on the interrupting fault and nominal current and creates a current zero instantly. The scheme can typically interrupt DC fault and nominal current within 8-10 milliseconds.

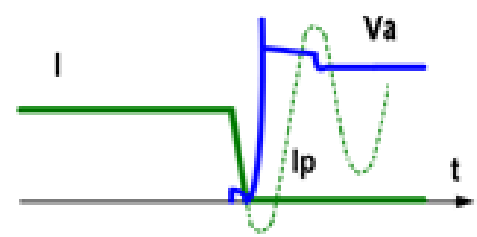

Figure 1. Forced current zero formation scheme

A HVDC grid will be required to operate the healthy lines continuously, even if a voltage collapse at the remote end occurs due to a fault. Rapid fault clearing is essential for DCCB even though the requirement varies depending on: 1) DC transmission system configurations, 2) Voltage Source Converter (VSC) design, 3) transmission capacity, 4) DC reactor connected in series with the line / cable, and
5) impedance of the line / cable. Forced current zero formation scheme is suitable for HVDC grid application from point of view of the fault clearing time, a capital Expenditure (CAPEX), and losses.

In this paper, the requirements for DCCB were analytically evaluated using a four-terminal radial HVDC network model. 


\section{DCCB REQUIREMENTS FOR MULTI-TERMINAL HVDC GRID}

\section{A. System model}

The requirements for DCCB such as DC fault current level and DC fault clearing time are investigated with a multi-terminal radial HVDC network model shown in Figure 2. This model consists of a four-terminal HVDC network with four VSC stations connected via DC lines as shown in Figure 2. The lengths of each DC line were set to $120 \mathrm{~km}, 240 \mathrm{~km}$ and $360 \mathrm{~km}$, similar to the radial UHV AC network that was used to evaluate the circuit breaker requirements.[6] Simulations were performed in each case when DC lines consist of cable or OHL. The capacities of each VSC converter stations (C/S) range from $900 \mathrm{MW}$ to $1200 \mathrm{MW}$, and the transmission capacity of the system is 2.1 GW. In the analysis, a DC pole to pole fault is considered near B-C/S.

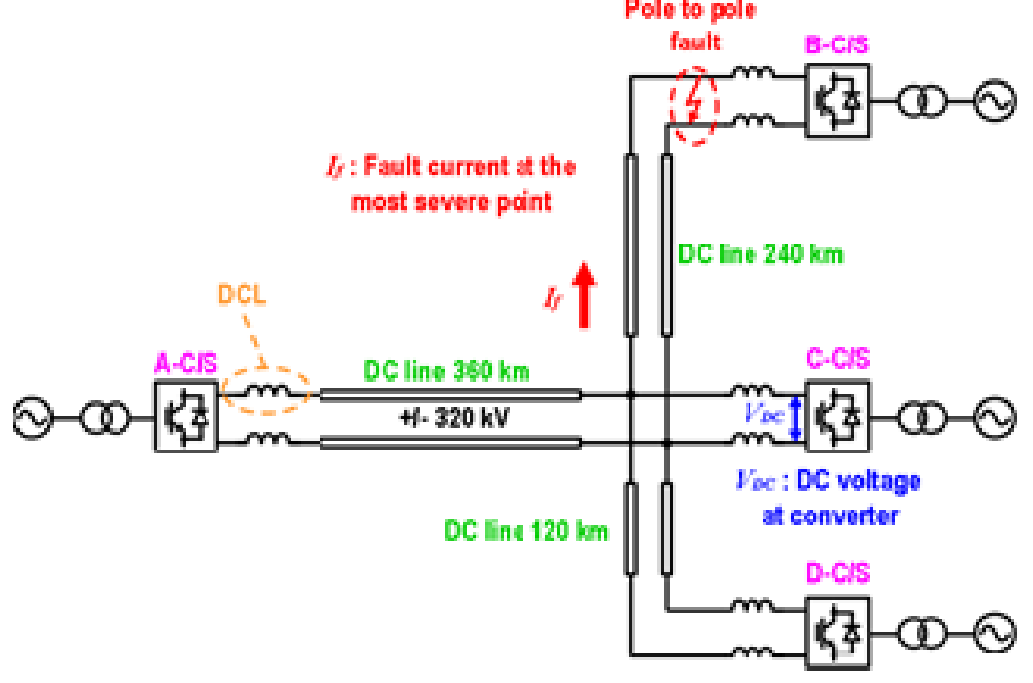

Figure 2. Multi-terminal radial HVDC network model

A VSC converter cannot continue operation when the DC system voltage typically drops below $80 \%$ of the nominal voltage depending on the design parameter (e.g. modulation index). Therefore, the DCCB is required to clear a fault rapidly in order to continue power transmission on a healthy line, before the system voltage drops to $0.8 \mathrm{PU}$ due to the impact of a fault that has occurred on a remote line. The time for the system voltage to drop to $0.8 \mathrm{PU}$ due to a remote fault can be protracted by inserting a series connected reactor (DCL) to the DC lines.

\section{B. Analytical results in cable system}

Figure 3 shows some analytical results of the DC voltage $V D C$ (the pole to pole voltage shown in Figure 2) at each C/S for various DCL reactor values when a pole to pole fault occurs near B-C/S. The DC lines in the fourterminal HVDC network consist of cables in this case.

The voltage at B-C/S near immediately drops at the instance of a fault in a rate of decay of voltage determined by the line impedance and DCL reactor. The voltage at CC/S, D-C/S and A-C/S located $240 \mathrm{~km}$ to $600 \mathrm{~km}$ away from the fault location gradually drops after fault occurrence, but the rate of decay is not as severe due to impedance increase with the larger reactance of DCL reactor and transmission lengths as well as travelling wave phenomenon from longer propagation distance from the fault location.

Simulations show that by increasing the reactance of the line and having longer distances from the fault location the voltage drop at a remote converter can be mitigated therefore allowing a longer DC fault clearing time threshold for the DCCB. Table 1 summarizes the results of the simulations showing fault clearing times for DCCB, which is set that the converter DC voltage not to drop below $0.8 \mathrm{PU}$ of the system voltage after a fault occurrence, while varying the value of the DCL reactor at each C/S. Although it doesn't indicate a perfect correlation between the speed of the voltage drop and distance from the fault due to transient oscillation and system parameter differences of each C/S (e.g. converter capacity), but DC voltage tends to drop slowly with longer distance from the fault. The result indicates that the DC fault clearing time could be longer than 10 milliseconds when a larger DCL reactor in the range of $300 \mathrm{mH}$ or more is connected to a main circuit in series. 


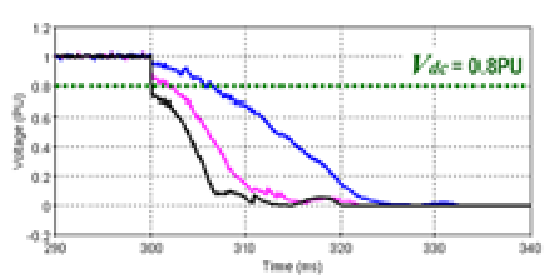

(a) B-C/S (near the fault)

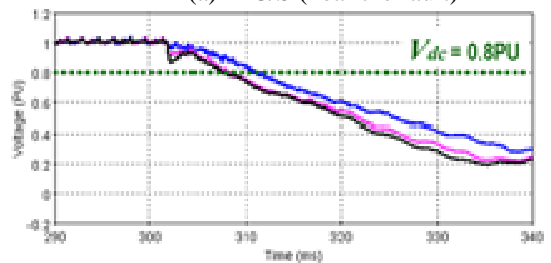

(c) D-C/S (360 km from the fault)

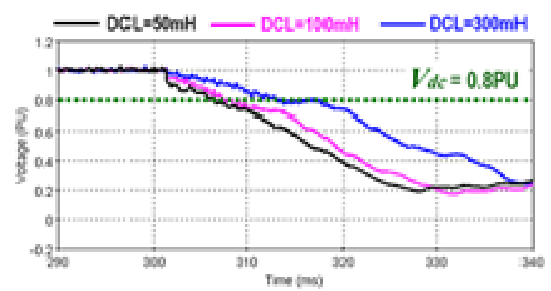

(b) C-C/S (240 km from the fault)

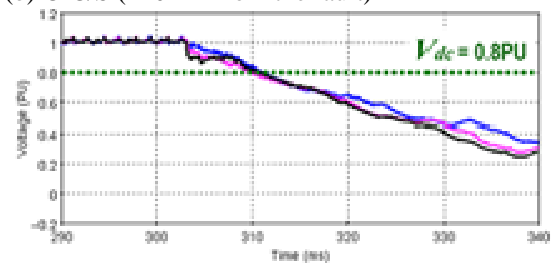

(d) A-C/S (600 km from the fault)

Figure 3. DC Voltage behaviour at each C/S in cable system

TABLE I. DC FAULT CLEARING TIMES AT EACH C/S IN CABLE SYSTEM

\begin{tabular}{|c|c|c|c|c|}
\hline \multirow{2}{*}{$\begin{array}{c}\text { DCL Reactor } \\
(\mathrm{mH})\end{array}$} & \multicolumn{4}{|c|}{ Time for DC voltage at converter to drop to 0.8 PU, $t$ (ms) } \\
\cline { 2 - 5 } & $\begin{array}{c}\text { B-C/S } \\
\text { (near) }\end{array}$ & $\begin{array}{c}\text { C.C/S } \\
(240 \mathrm{~km} \text { away) }\end{array}$ & $\begin{array}{c}\text { D.C/S } \\
(360 \mathrm{~km} \text { away })\end{array}$ & $\begin{array}{c}\text { A.C/S } \\
(600 \mathrm{~km} \text { away })\end{array}$ \\
\hline 50 & 0.002 & 5.92 & 7.36 & 10.18 \\
\hline 100 & 1.52 & 7.38 & 8.08 & 9.62 \\
\hline 300 & 5.70 & 11.72 & 10.90 & 10.58 \\
\hline
\end{tabular}

Another important requirement for DCCBs is DC fault current. In Figure 2 the fault current (If) through the cable connected to B-C/S is the most severe case, because the fault currents from three converters of $\mathrm{A}, \mathrm{C}$ and $\mathrm{D}-\mathrm{C} / \mathrm{S}$ flow into the fault location. Figure 4 shows the DC fault current behaviour of If for various DCL reactor values in the four-terminal HVDC network.

When a fault occurs the connected poles immediately discharge at the fault and thus the fault current is in the range of 12 to $15 \mathrm{kA}$. Then the discharged current oscillates with a resonant frequency determined by the cable impedance. The fault current continues to increase up to $30 \mathrm{kA}$ due to the fault currents flowing from the remote converters located at $\mathrm{A}, \mathrm{C}$ and $\mathrm{D}-\mathrm{C} / \mathrm{S}$. The simulation shows that the DC fault current is $15 \mathrm{kA}$ for $300 \mathrm{mH}$ DCL reactor and $21 \mathrm{kA}$ for $100 \mathrm{mH}$ DCL reactor after 10 milliseconds from the occurrence of the fault.

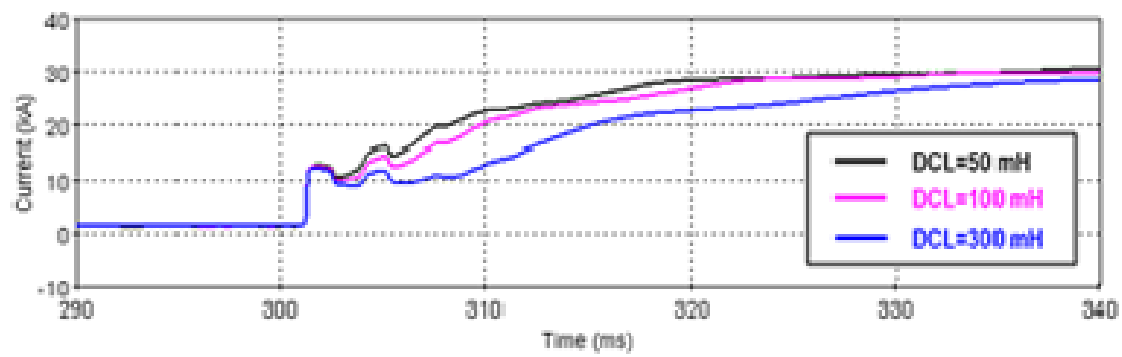

Figure 4. DC fault current behaviour of If in cable system 


\section{Analytical results in OHL system}

Figure 5 shows some analytical results of the DC voltage VDC when DC lines in the four-terminal HVDC network consist of OHL (Over Head Line). DC line length and other system conditions are the same as cable system. Furthermore, Table 2 shows the time for DC voltage at converter to drop to $0.8 \mathrm{PU}$ in this case. Since the inductance of OHL is larger than that of cable, the speed of the voltage drop is slower, and by inserting $50 \mathrm{mH}$ DCL reactor, the time for DC voltage to drop 0.8 PU becomes longer than 10 milliseconds.

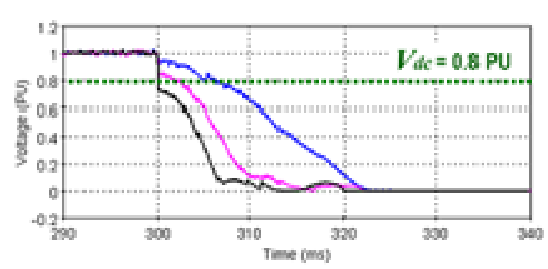

(a) B-C/S (near the fault)

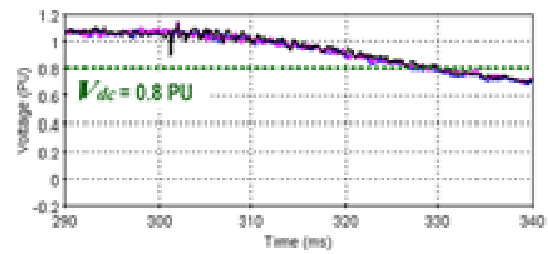

(c) D-C/S (360 km from the fault)

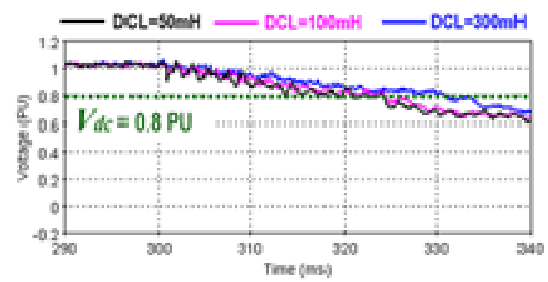

(b) C-C/S (240 km from the fault)

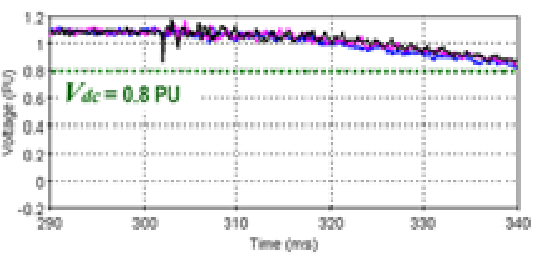

(d) A-C/S (600 km from the fault)

Figure 5. DC Voltage behaviour at each C/S in OHL system

TABLE II. DC FAULT CLEARING TIMES AT EACH C/S IN OHL SYSTEM

\begin{tabular}{|c|c|c|c|c|}
\hline \multirow{2}{*}{$\begin{array}{c}\text { DCL Reactor } \\
(\mathrm{mH})\end{array}$} & \multicolumn{4}{|c|}{ Time for DC voltage at converter to dropto 0.8 PU, $t$ (ms) } \\
\cline { 2 - 5 } & $\begin{array}{c}\text { B-C/S } \\
(\text { near) }\end{array}$ & $\begin{array}{c}\text { C-C/S } \\
(240 \mathrm{~km} \text { away) }\end{array}$ & $\begin{array}{c}\text { D-C/S } \\
(360 \mathrm{~km} \text { away) }\end{array}$ & $\begin{array}{c}\text { A-C/S } \\
(600 \mathrm{~km} \text { away) }\end{array}$ \\
\hline 50 & 0.002 & 13.76 & 28.26 & 44.50 \\
\hline 100 & 1.78 & 19.04 & 26.80 & 44.14 \\
\hline 300 & 4.94 & 30.84 & 26.80 & 40.28 \\
\hline
\end{tabular}

Figure 6 shows DC fault current at the most severe point (If in Figure 2) in the OHL four-terminal HVDC network. The fault current is less than $8 \mathrm{kA}$ after 10 milliseconds from the occurrence of the fault in every case due to the suppression by OHL inductance. These results show that DCCB requirements in OHL HVDC system are relaxed than that of cable HVDC system.

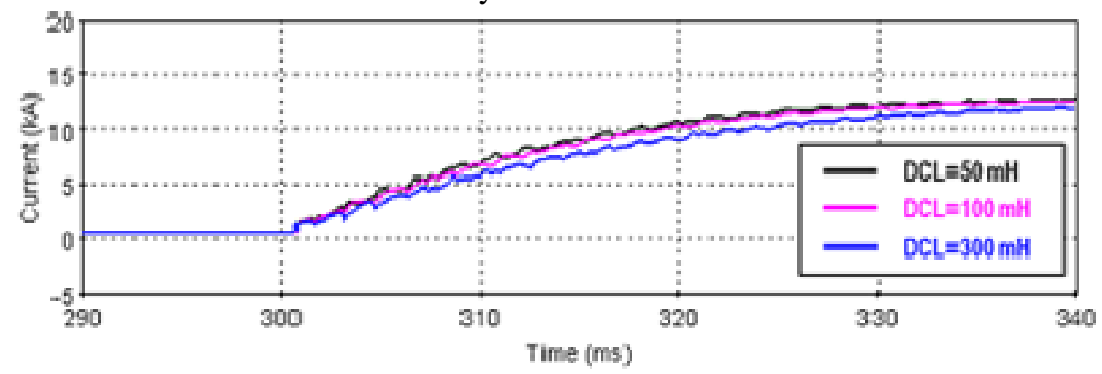

Figure 6. DC fault current behaviour of If in OHL system

\section{DCCB requirements for radial HVDC network}

These analytical results indicate that the DC fault interruption requirement for DCCB in the four-terminal +/-320 kV radial HVDC network model with appropriate value of DCL is less than $15 \mathrm{kA}$. Furthermore, they indicate that the fault clearing time in order to continue power transmission at the remote C/S located $240 \mathrm{~km}$ away from fault location is longer than 10 milliseconds in this model. The requirements make it feasible to apply a 
mechanical DCCB with the forced current zero formation scheme to HVDC grid line protection.

\section{CONCLUSIONS}

The requirements for the DCCB's operation were evaluated using a four-terminal +/-320 kV radial HVDC network model. By inserting appropriate value of DCL reactors into the network model and upon simulating pole to pole fault, 1) the short circuit current levels where limited to values less than $15 \mathrm{kA}$ and 2) the DC fault clearing times where longer than 10 milliseconds, while maintaining power transmission at a remote C/S located $240 \mathrm{~km}$ away from fault location. These two requirements make it feasible to apply a mechanical DCCB with the forced current zero formation scheme for HVDC grid line protection.

\section{REFERENCES}

[1] A. Lee et al., "Arc-circuit instability: HVDC circuit breaker concept based on SF6 puffer technology", IEE GD-82, pp.116-119

[2] H. Ito et al., "Instability of DC Arc in SF6 circuit breaker", IEEE transactions on Power Delivery, Vol.12, No.4, pp.1508-1513, 1997

[3] S. Hara et al., "Fault protection of metallic return circuit of Kii channel HVDC system”, IEE GD-95, pp.132-137

[4] CIGRE WG B4.52, "HVDC grid feasibility study, Appendix H: Switching DC in an HVDC system”, Technical Brochure 533, 2013

[5] M. Callavik et al., "Hybrid HVDC breaker", ABB grid systems, Technical paper, Nov. 2012

[6] CIGRE WG A3.28, "Switching phenomena for EHV and UHV equipment”, CIGRE Technical Brochure 570, February 2014 